\title{
Interventions to Reduce Blatant and Subtle Sexual Orientation- and Gender Identity Prejudice (SOGIP): Current Knowledge and Future Directions
}

\author{
Florien M. Cramwinckel* \\ Utrecht University \\ Daan T. Scheepers \\ Leiden University \\ Jojanneke van der Toorn \\ Utrecht University and Leiden University
}

Given its prevalence and impact, it is important that prejudice against sexual-and gender identity minorities is reduced and that negative behaviors against these minorities are prevented. We introduce and provide a definition of the term Sexual Orientation and Gender Identity Prejudice (SOGIP), and discuss its determinants and configurations as well as ways to measure it. Furthermore, we review the recent social psychological literature on SOGIP-reducing interventions, identify scientific knowledge gaps regarding these interventions, and offer recommendations on how to apply the available knowledge to real-life situations. We conclude that there are many interventions currently being employed to target SOGIP with some seeming more effective than others. Particularly promising interventions are those aimed at evoking empathy and perspective taking and those aimed at developing alliances between minority and majority members. However, there is still room for improvement. Overall, little empirical evidence speaks to the robustness of intervention effects, its underlying mechanisms, duration, and boundary conditions. Researchers should focus on all aspects of SOGIP (i.e., sexual orientation prejudice as well as gender identity prejudice); different expressions of prejudice (i.e., blatant and subtle), actual behavior towards minorities, and on both perpetrators and targets of prejudice. By joining forces, researchers and

\footnotetext{
* Correspondence concerning this article should be addressed to Florien Cramwinckel, Department of Interdisciplinary Social Science, Utrecht University, Heidelberglaan 1, 3584 CS, Utrecht, The Netherlands [e-mail: F.M.Cramwinckel@gmail.com].
}

183 
practitioners should aim to overcome practical and theoretical obstacles in evaluating the effectiveness of interventions. Policy makers should support initiatives that test, improve, implement and distribute intervention programs, and can help bring together researchers and practitioners.

Although many people (especially in the western world) consider themselves to be supportive of equal rights for sexual and gender minorities, prejudice against Lesbians, Gay men, Bisexual men and women, people who are Transgendered, and Queer (LGBTQ's) is still prevalent today (Herek \& McLemore, 2013). Hatecrimes against LGBTQs occur frequently (FBI, 2015). Even in the Netherlands-a progressive country-LGBTQ teens are bullied more than four times as often as their heterosexual peers (Kuyper, 2015). The consequences are severe: Suicide (attempts), isolation and depression are much higher amongs LGBTQ teenagers than among heterosexual teenagers (e.g., Haas et al., 2010; Hong, Espelage, \& Kral, 2011; Marshal et al., 2011). One of the most horrific examples of antiLGBTQ violence may be the Orlando, Florida nightclub shooting where a single gunman killed 49 people and wounded 53 others (CNN, 2016).

Given its prevalence and impact, it is important that sexual orientation- and gender identity prejudice is reduced and that negative behaviors are prevented. In this article, we aim to contribute to these goals in four ways. First, we define sexual orientation- and gender identity prejudice and discuss its determinants, forms and ways to measure it. Second, we provide an overview of the recent literature on interventions. Third, we identify knowledge gaps regarding these interventions, and provide guidelines for how to address these gaps. Finally, we offer recommendations on how to apply scientific knowledge on this topic in reallife situations. As such, this article is relevant for academics, practitioners and policy-makers.

Central to our analysis is the notion that sexual orientation- and gender identity prejudice have changed from more blatant forms to more subtle forms and that this has implications for interventions.

\section{Sexual Orientation- and Gender Identity Prejudice (SOGIP)}

A first step in reducing the incidence of a given phenomenon is providing a clear definition of what it entails. This may be particularly relevant for research on sexual orientation- and gender identity prejudice. There is an abundance of terms to describe negativity toward nonheterosexual and/or noncisgendered ${ }^{1}$ individuals and groups, such as heterosexism, homophobia, biphobia, transphobia, homonegativity, and sexual stigma, to name a few (e.g., Herek \& McLemore,

\footnotetext{
${ }^{1}$ For people who are cisgendered, their biological sex corresponds with their gender identity. For people who are transgendered, their biological sex does not correspond with their gender identity.
} 
2013; Herek, 2000; 2007; Morrison \& Morrison, 2003; Walch, Swain, Fransisco, Breaux, \& Sjoberg, 2012). Many of these terms seem to be exclusivively focused on prejudice against one specific minority group, most often homosexual men. This is problematic because prejudice affects more subgroups than the ones explicitly mentioned in this exclusive terminology. Some of these underrepresented subgroups may be particularly frequent targets of prejudice in real-life (e.g., people who are transgendered). To stimulate such a broader view, in this article we aimed to include examples of research on underrepresented samples.

In this article, we use the term Sexual Orientation and Gender Identity Prejudice, as well as the abbreviation SOGIP. Based on Herek (2000), we define SOGIP as negative attitudes about certain behaviors, individuals or groups based on-or related to - their (perceived) sexual orientation, (perceived) gender identity, gender role or gender expression. It is important to note that although theoretically this definition could include prejudice toward majority members (i.e., people who are heterosexual and/or cisgendered), in reality, SOGIP will almost always be aimed at those who deviate from the heterosexual and/or cisgender norm (Herek, 2000). Furthermore, although sexual orientation prejudice and gender identity prejudice are theoretically distinct, there are good reasons to discuss, investigate, and target them jointly. One of these reasons is that sexual orientation prejudice is strongly related to, and may even be rooted in, the rejection of gender diversity.

\section{Determinants of SOGIP}

Gender nonconformity. Although various factors play a role in determining sexual orientation prejudice and violence (e.g., Buijs, Hekma, \& Duyvendak, 2011) most research suggests that discomfort with gender role violations may explain much of it. For example, in one study (Lick \& Johnson, 2014), participants evaluated faces of gay/lesbian or straight men and women. Irrespective of the sexual orientation of the target person, the faces also varied in terms of whether they were gender-typical (i.e., feminine women) or gender-atypical (i.e., masculine women). Participants evaluated the faces and indicated the perceived sexual orientation of the target person. Results, first of all, demonstrated prejudice toward lesbians: Regardless of the accuracy of categorizations, female faces that were categorized as lesbian were evaluated more negatively than faces that were categorized as heterosexual. Results also demonstrated gender identity prejudice: Gender-atypical female faces were evaluated more negatively than gender-typical female faces. Because gender-atypical female faces were more likely to be categorized as lesbian, gender atypicality partly explains sexual orientation prejudice (i.e., negative reactions based on-or related to-the target's [perceived] sexual orientation). It is noteworthy that these effects only appeared for lesbian women, and not for gay men, which was explained as stemming from gay men being 
judged more on the basis of their behavior, while lesbian women are judged more on the basis of their appearance (Lick \& Johnson, 2014).

There is also direct evidence for a relation between traditional gender-role beliefs and prejudice toward lesbians (Parrott \& Gallagher, 2008) and gay men (Parrott, 2009). Moreover, the acceptance of gender nonconformity mediates the link between contact with sexual minorities and sexual orientation prejudice (Collier et al., 2012). More specifically, in a sample of students from eight high schools in the Netherlands, these researchers assessed the number of openly gay or lesbian people that the participants knew in their direct environment, and their attitudes toward gays and lesbians. Participants also indicated how acceptable they found persons who deviated from gender norms and how they felt about people with different sexual orientations. Results showed that more contact with sexual minorities led to higher acceptance of gender nonconformity which in turn led to lower sexual orientation prejudice.

Importantly, it is not just people with strong convictions about gender roles who show prejudice; rather, it is often the people who are most concerned about losing their own gender identity who show the strongest SOGIP. Research shows that men who were concerned with losing their masculinity or who experienced more stress in response to gender norm deviations tended to be higher in sexual orientation prejudice and more angry and aggressive toward gay men (e.g., Glick, Gangl, Gibb, Klumpner, \& Weinberg, 2007; Hudepohl, Parrott, \& Zeichner, 2010; Stotzer \& Shih, 2012; Vincent, Parrott, \& Peterson, 2011; see also Falomir-Pichastor \& Mugny, 2009). For example, Bosson Weaver, Caswell, and Burnaford (2011) provided heterosexual male college students with false feedback about their personality. Participants learned that they had a feminine (i.e, the threat condition) or a masculine gender identity (i.e., the affirmation condition). Hereafter, participants played an online game where they could deliver noiseblasts to a fictitious gay peer. Participants whose gender identity was threatened behaved more aggressively. Importantly, this effect only occurred when participants had revealed their own heterosexual orientation earlier in the experiment, but not when they did not have the opportunity to do so. Apparently, when heterosexual men's gender status was questionable (either because it was threatened by feedback, or because they did not have a chance to reveal their heterosexuality), they behaved aggressively toward gay peers.

In summary, gender identity prejudice relates to sexual orientation prejudice in different ways. Traditional gender-role beliefs and threats to one's gender identity directly predict sexual orientation prejudice. Moreover, perceptions of gender nonconformity also indirectly predict sexual orientation prejudice through (mis)perceptions of sexual orientation (Lick \& Johnson, 2014; Parrott \& Gallagher, 2008; Stotzer \& Shih, 2012). The acceptance of gender nonconformity is an important mediating process between contact with LGBTQs and lower prejudice against them. 
Demographic characteristics. Demographic characteristics also play a role in explaining SOGIP. Men, in general, display higher levels of SOGIP than women (e.g., Chaux \& Léon, 2016; Haney, 2016; Lee \& Cunningham, 2016; Monto \& Supinski, 2014; Romero, Morera, \& Wiebe, 2015). This sex effect was corroborated in an analysis of attitudes toward homosexuality in 79 countries, which furthemore demonstrated that being older (vs. younger), having lower levels of education (vs. higher levels), lower levels of income/social status (vs. higher levels), and being married (vs. being unmarried), predicted higher levels of SOGIP (Jäckle \& Wenzelburger, 2015). Above and beyond the influence of these factors, however, is the influence of religiosity on SOGIP. Religious people tend to display higher levels of SOGIP than nonreligious people, although there are differences between specific religions (Jäckle \& Wenzelburger, 2015). For instance, Muslims tend to be higher in SOGIP than Catholics and Protestants, who in turn are higher in SOGIP than people adhering to eastern religions (e.g., Hinduism, Buddhism and Taoism) or nonreligious people.

There is also research examining the psychological process underlying the relationship between religiosity and SOGIP. Van der Toorn, Jost, Packer, Noorbaloochi, and Van Bavel (2017) demonstrated that this relationship is mediated by political conservatism-in particular resistance to change. They found that the more religious heterosexual respondents were, the more inclined they were to maintain the status quo, which in turn predicted opposition to same-sex marriage, presumably because sexual and gender minorities challenge traditional forms of romantic relationships, gender roles and gender expressions.

To summarize, there are multiple determinants of SOGIP. Some factors (e.g., one's age, gender or religious affiliation) may be relatively hard to change, and therefore difficult to target with interventions. Because the focus of this article is on interventions to reduce SOGIP, we will focus mostly on factors that can be targeted in an intervention.

\section{Blatant Versus Subtle Prejudice}

Interventions that target SOGIP should take into account that its expression can take different forms. These differences in forms may have consequences for (assessing) the effectiveness of interventions. For example, over the last few decades, prejudice has changed from more blatant to more subtle forms. Due to social norms and legislation, blatant prejudice has become less acceptable or even illegal (at least in many western societies). However, this does not mean that prejudice has faded away. On the contrary, just as a virus can mutate and thereby become more difficult to cure, prejudice has changed into (more subtle) forms that are not only more difficult to recognize but also to combat (Dovidio \& Gaertner, 1998, 2004). Despite the fact that blatant SOGIP is still prevalent (especially when compared to other forms of prejudice; Herek \& McLemore, 2013), researchers 
have noted that in order to fully understand the nature of SOGIP, and to find ways to intervene, it is also necessary to address subtle forms of SOGIP (Morrison \& Morrison, 2003).

Table 1 displays different types of SOGIP that vary in the extent to which they are relatively blatant versus subtle. ${ }^{2}$ Blatant prejudice, on the one hand, is characterized by explicit hostile attitudes and emotions (e.g., hate) toward sexual and gender minorities (e.g., Herek, 1988; Morrison \& Morrison, 2003). Moreover, blatant SOGIP is often rooted in moral convictions based on religion or other ideologies, and is behaviorally expressed in explicit negative behaviors or aggression (Herek \& McLemore, 2013). Subtle prejudice, on the other hand, is characterized by implicit negative associations, mild negative emotions (e.g., discomfort rather than hate), and nonverbal behavioral expressions (e.g., avoiding physical contact; Dovidio, Gaertner, \& Pearson, 2016; Dovidio \& Gaertner, 2004). Moreover, subtle prejudice can also be expressed in the form of absence of positive behaviors or attitudes (e.g., Dovidio \& Gaertner, 2004) or denial that sexual orientation prejudice is still a problem nowadays (McConahay, 1986; Morrison \& Morrison, 2003; Morrison, Morrison, \& Franklin, 2009). These characteristics make subtle prejudice particularly hard to prove, and thus harder to combat (Barreto \& Ellemers, 2015).

Another characteristic of subtle SOGIP is its ambivalent nature (Hoffarth \& Hodson, 2014), meaning that people simulteaneously hold positive and negative beliefs regarding sexual and gender minorities. For example, although $90 \%$ of heterosexual adults in the Netherlands think that sexual minorities should be free to live their lives as they wish, they are also about three times more likely to find it offensive when two men kiss in public rather than when a man and a woman kiss in public (Kuyper, 2015). Thus, although holders of subtle SOGP often explicitly support formal rights and legal protection for sexual and gender minorities, they simultaneously grant these minorities fewer informal privileges such as being able to express one's affection for one's partner in public (Doan, Loehr, \& Miller, 2014).

Importantly, research has shown that these ambivalent attitudes are not harmless. That is, despite the fact that ambivalent attitudes comprise both positive and negative beliefs, the negative ones seem to prevail in the expression of these beliefs in (subtle) behavior. People who felt ambivalent about sexual diversity, were eventually less likely to empathize with a LGBTQ person being bullied, and were less likely to oppose to this bullying behavior (Hoffarth \& Hodson, 2014). Thus, when it comes to actually standing up for and supporting LGBTQs, not much

\footnotetext{
${ }^{2}$ We do not aspire to provide an exhaustive overview, but rather aim to focus on several types of prejudice that we think are relevant for the current paper and/or did not yet receive systematic research attention.
} 
Table 1. Different Types and Measures of Sexual Orientation- and Gender Identity Prejudice (SOGIP)

\begin{tabular}{|c|c|c|c|}
\hline $\begin{array}{l}\text { Target of } \\
\text { prejudice }\end{array}$ & Blatant/subtle & Form/measure/scale & Example items/procedure \\
\hline \multirow[t]{9}{*}{ Lesbian/gay } & \multirow[t]{4}{*}{ Blatant } & $\begin{array}{l}\text { Old-fashioned prejudice: Attitudes } \\
\text { toward Gay Men Scale (ATG) and } \\
\text { Attitudes toward Lesbians Scale (ATL; } \\
\text { Herek, 1988, 1997) }\end{array}$ & $\begin{array}{l}\text { "Male homosexuality is a perversion" } \\
\text { (ATG) } \\
\text { "Female homosexuality is an inferior } \\
\text { form of sexuality" (ATL) }\end{array}$ \\
\hline & & $\begin{array}{l}\text { Moral Condemnation Scale (Buck et al., } \\
\text { 2013) }\end{array}$ & $\begin{array}{l}\text { "According to my personal morals, } \\
\text { homosexuality is wrong" }\end{array}$ \\
\hline & & $\begin{array}{l}\text { Negative behaviors: Self-Report of } \\
\text { Behavior Scale-Revised (SBS-R; } \\
\text { Roderick et al., 1998) }\end{array}$ & $\begin{array}{l}\text { "Made verbal threat" } \\
\text { "Wrote graffiti" }\end{array}$ \\
\hline & & $\begin{array}{l}\text { Aggression: Adapted version of the Taylor } \\
\text { aggression paradigm (Parrot \& Lisco, } \\
\text { 2015; Parrot, 2009) }\end{array}$ & $\begin{array}{l}\text { Heterosexual participants can administer } \\
\text { electrical shocks to a fictitious } \\
\text { homosexual opponent. Physical } \\
\text { aggression is defined as the intensity } \\
\text { and duration of the shocks selected. }\end{array}$ \\
\hline & \multirow[t]{2}{*}{$\begin{array}{l}\text { Moderately } \\
\text { blatant }\end{array}$} & $\begin{array}{l}\text { General prejudice (thermometer) } \\
\text { measure(Haddock, Zanna, \& Esses, } \\
\text { 1993) }\end{array}$ & $\begin{array}{l}\text { "Provide a number between } 0 \text { and } 100 \text { to } \\
\text { indicate your overall evaluation of a } \\
\text { typical member of this group" }\end{array}$ \\
\hline & & $\begin{array}{l}\text { Homophobia Scale (Wright, Adams, \& } \\
\text { Bernat, 1999) }\end{array}$ & $\begin{array}{l}\text { "Gay people make me nervous" } \\
\text { "I feel that you cannot trust a person who } \\
\text { is homosexual" }\end{array}$ \\
\hline & \multirow[t]{3}{*}{ Subtle } & $\begin{array}{l}\text { Modern Homonegativity Scale (Morrison } \\
\text { \& Morrison, 2003). Measures the beliefs } \\
\text { that:(a) gay men and lesbian women are } \\
\text { making illegitimate (or unnecessary) } \\
\text { demands for changes in the status quo; } \\
\text { (b) discrimination against gay men and } \\
\text { lesbian women is a thing of the past; and } \\
\text { (c) gay men and lesbian women } \\
\text { exaggerate the importance of their } \\
\text { sexual orientation thereby perpetuating } \\
\text { their own marginalization. }\end{array}$ & $\begin{array}{l}\text { "Lesbians should stop shoving their } \\
\text { lifestyle down other people's throats" } \\
\text { "Many gay men use their sexual } \\
\text { orientation so that they can obtain } \\
\text { special privileges" }\end{array}$ \\
\hline & & $\begin{array}{l}\text { Homonegativity as Discomfort Scale } \\
\text { (Monto \& Supinski, 2014). } 12 \text { vignettes } \\
\text { that are designed to measure discomfort } \\
\text { in the presence of same-sex couples }\end{array}$ & $\begin{array}{l}\text { "You go out with some friends on a } \\
\text { Saturday night and choose a welcoming } \\
\text { bar that you have never been to. Once } \\
\text { you get inside you realize that almost } \\
\text { all of the patrons are female couples. } \\
\text { There is a woman with her arms around } \\
\text { another woman in a booth to your left. } \\
\text { How does this make you feel?" }\end{array}$ \\
\hline & & & $\begin{array}{l}\text { "You invite a coworker who you like but } \\
\text { hove never spent time with outside of } \\
\text { work to party you're throwing. He } \\
\text { shows up holding hands with a man } \\
\text { you don't know. How does this make } \\
\text { you feel?" }\end{array}$ \\
\hline
\end{tabular}


Table 1. Continued

\begin{tabular}{|c|c|c|c|}
\hline $\begin{array}{l}\text { Target of } \\
\text { prejudice }\end{array}$ & Blatant/subtle & Form/measure/scale & Example items/procedure \\
\hline & & $\begin{array}{l}\text { Implicit negative associations: Implicit } \\
\text { Association Test (IAT; Burke et al., } \\
\text { 2015; Inbar, Pizarro, Knobe, \& Bloom, } \\
\text { 2009) }\end{array}$ & $\begin{array}{l}\text { A set of images and words representing } \\
\text { same-sex couples and heterosexual } \\
\text { couples (e.g., wedding cake toppers, } \\
\text { bathroom signs, pictures of couples). } \\
\text { These need to be matched with words } \\
\text { with negative and positive valence. }\end{array}$ \\
\hline & & $\begin{array}{l}\text { Attitudes Toward Same-Sex Marriage } \\
\text { Scale (ATSM; Pearl \& Galupo, 2007; see } \\
\text { also Lannutti \& Lachlan, 2007). Note } \\
\text { that higher scores on this scale indicates } \\
\text { more positive attitudes, and lower scores } \\
\text { indicate more prejudiced attitudes. }\end{array}$ & $\begin{array}{l}\text { "Same-sex marriage undermines the } \\
\text { meaning of the traditional family" (r) } \\
\text { "Same-sex marriage will lead to moral } \\
\text { decay of society" (r) }\end{array}$ \\
\hline & & $\begin{array}{l}\text { Informal privileges: Interactional and } \\
\text { subtle advantages that dominant groups } \\
\text { enjoy over minority groups (e.g., Doan, } \\
\text { Loehr, \& Miller, 2014; Kuyper, 2015) }\end{array}$ & $\begin{array}{l}\text { "To what extent do you agree or disagree } \\
\text { that it is okay for [couple members' } \\
\text { names] to tell others that they are a } \\
\text { couple?" }\end{array}$ \\
\hline & & & $\begin{array}{l}\text { "To what extent do you agree or disagree } \\
\text { that it is okay for [couple members' } \\
\text { names] to hold each other's hands in a } \\
\text { park?" }\end{array}$ \\
\hline & & $\begin{array}{l}\text { Fear of Social Contagion Scale (Buck } \\
\text { et al., 2013): Concerns about being } \\
\text { misperceived as lesbian/gay as a result of } \\
\text { interacting with a lesbian/gay individual }\end{array}$ & $\begin{array}{l}\text { "If I was hanging out with a homosexual } \\
\text { person, I would worry that other people } \\
\text { would think I was a homosexual too" } \\
\text { "If I had to interact with a homosexual } \\
\text { person of my same gender, I would } \\
\text { worry that he or she would flirt with } \\
\text { me" }\end{array}$ \\
\hline $\begin{array}{c}\text { Lesbian/gay/ } \\
\text { bisexual/ } \\
\text { queer }\end{array}$ & Subtle & $\begin{array}{l}\text { Microaggression: Everyday brief, } \\
\text { low-intensity events that convey negative } \\
\text { messages about LGBQ people } \\
\text { (Microaggression on College Campuses } \\
\text { Scale; LGBQ-MCCS; Woodford, } \\
\text { Chonody, Kulick, Brennan, \& Renn, } \\
\text { 2015) }\end{array}$ & $\begin{array}{l}\text { "Someone said or implied that LGBQ } \\
\text { people engage in unsafe sex because of } \\
\text { their sexual orientation" } \\
\text { "I heard someone say 'that's so gay' to } \\
\text { describe something as negative, stupid, } \\
\text { or uncool" }\end{array}$ \\
\hline $\begin{array}{l}\text { Lesbian/gay/ } \\
\text { bisexual/ } \\
\text { people } \\
\text { who are } \\
\text { transgen- } \\
\text { dered }\end{array}$ & Subtle & $\begin{array}{l}\text { Positive behaviors }^{3} \text { : Protesting against } \\
\text { homophobic behavior and/or explicitly } \\
\text { LGBT-affirming behaviors } \\
\text { (Participant Role Questionnaire; Poteat \& } \\
\text { Vecho, 2016; Explicit LGBT-affirming } \\
\text { behaviors Poteat, 2015) }\end{array}$ & $\begin{array}{l}\text { "I tried to get the student(s) who started it } \\
\text { to stop" } \\
\text { "I supported the student who was } \\
\text { targeted" (Poteat \& Vecho, 2016) } \\
\text { "I voiced strong support for lesbian, gay, } \\
\text { bisexual, or transgender (LGBT) } \\
\text { individuals" } \\
\text { "I spoke about addressing inequalities } \\
\text { faced by LGBT individuals" (Poteat, } \\
\text { 2015) }\end{array}$ \\
\hline
\end{tabular}

(Continued)

${ }^{3}$ Please note that the absence of positive behaviors can be interpreted as an expression of subtle SOGIP, while the occurrence of positive behaviors are blatant indicators of support for sexual and gender minorities. 
Table 1. Continued

\begin{tabular}{|c|c|c|c|}
\hline $\begin{array}{l}\text { Target of } \\
\text { prejudice }\end{array}$ & Blatant/subtle & Form/measure/scale & Example items/procedure \\
\hline Bisexuals & Subtle & Biphobia scale (Eliason, 1997) & $\begin{array}{l}\text { "Bisexuals tend to have more sexual } \\
\text { partners than heterosexuals" } \\
\text { "Bisexuals are just going through a phase } \\
\text { or experimenting with sex" }\end{array}$ \\
\hline $\begin{array}{l}\text { Gender } \\
\text { identity/ } \\
\text { People } \\
\text { who are } \\
\text { transgen- } \\
\text { dered }\end{array}$ & Blatant & $\begin{array}{l}\text { Genderism and Transphobia Scale (GTS; } \\
\text { Hill \& Willoughby, 2005) }\end{array}$ & $\begin{array}{l}\text { "A man who dresses like a woman is a } \\
\text { pervert" } \\
\text { "I have behaved violently towards a } \\
\text { woman because she was too masculine" }\end{array}$ \\
\hline $\begin{array}{l}\text { Gender } \\
\text { identity/ } \\
\text { expression }\end{array}$ & Subtle & $\begin{array}{l}\text { Gender Role Beliefs Scale (GRBS; Kerr \& } \\
\text { Holden, 1996); Meanings of } \\
\text { Adolescent Masculinity Scale (MAMS; } \\
\text { Oransky \& Fisher, 2009; see also Eisler } \\
\text { \& Skidmore, 1987); Male Role Norms } \\
\text { Scale (MRNS; Thompson \& Pleck, } \\
\text { 1986); Attitudes Toward Women Scale } \\
\text { (ATWS; Spence \& Hahn, 1997) }\end{array}$ & $\begin{array}{l}\text { "It is disrespectful for a man to swear in } \\
\text { the presence of a lady" (GRBS) } \\
\text { "It is not a guy's job to comfort a friend } \\
\text { who is upset" (MAMS) } \\
\text { "It bothers me when a man does } \\
\text { something that I consider 'feminine"" } \\
\text { (MRNS) } \\
\text { "Women should worry less about their } \\
\text { rights and more about becoming good } \\
\text { wives and mothers" (ATWS) } \\
\text { "A woman should not expect to go to } \\
\text { exactly the same places or to have quite } \\
\text { the same freedom of actions as a man" } \\
\text { (ATWS) }\end{array}$ \\
\hline
\end{tabular}

should be expected from ambivalently prejudiced people, despite the positive beliefs they hold.

An extreme example of the negative consequences of the ambivalent nature of SOGIP comes from research conducted in the Netherlands-a rather progressive country when it comes to LGBTQ rights. Buijs et al. (2011) provided evidence that even those who explicitly subscribed to the tolerant rhetoric in the Netherlands could become perpetrators of anti-LGBTQ violence. These researchers interviewed perpetrators who engaged in violent acts against homosexuals about their attitudes toward homosexuality. Despite the tolerant climate in the Netherlands, there were four aspects of male homosexuality that were a cause for resentment in these perpetrators (i.e., anal sex, feminine behavior, public displays of homosexuality, and attempts to seduce). For example, one perpretator assaulted his victims in the gym. During the interview, he told the researchers that "They are a little bit effeminate. That's okay, but then they shouldn't go to a place where you are expected to be a real man" (Buijs et al., 2011, p. 637). An important reason for resentment and violence seemed to be the perpetrators' adherence to traditional gender norms. When confronted with aspects of sexual- and gender diversity that collided with 
these traditional norms, they reacted violently. Thus, there appears to be a bounded tolerance in that people proclaim that they are "fine with homosexuals, as long as they act 'normal'." This is clearly expressed by some of the perpretators in these interviews, for example, by saing that "I'm perfectly fine with being being gay, right? But you are and you stay a man. So act like it" (Buijs et al., 2011, p. 637). Perhaps related to this is the finding that people sometimes fear that interaction with sexual and/or gender minority members results in them being misclassified as a sexual minority member themselves (Buck, Plant, Ratcliff, Zielaaskowski, \& Boerne, 2013). Thus, people can be 'fine' with sexual and gender minorities but at the same time want to keep their distance from them. This was also verbalized by the interviewed perpetrators, for example by stating that 'I'm willing to understand that they're gay, but they shouldn't get too close to me. I don't want that. If I can't make that clear in a decent way, I am forced to use other means" (Buijs et al., 2011, p. 640).

Behavioral expressions of the more subtle forms of SOGIP often take the form of "microaggressions" like using the expression "that's so gay" to describe something as negative or uncool. Apart from utterances and behaviors in interpersonal settings, microaggressions can also have a more structural character. An example of this climate is a school or workplace setting where it is acceptable to make jokes about LGBTQ people (Woodford, Chonody, Kulick, Brennan, \& Renn, 2015). When these kinds of jokes are made but not targeted at a specific LGBTQ invididual in the room, it creates a climate where anti-LGBTQ behaviors or remarks are permitted and perhaps even encouraged (i.e., by laughing).

In addition to microaggression, another behavioral aspect of subtle SOGIP is the absence of pro-LGBTQ behaviors. For LGBTQs coming out of the closet, support from non-LGBTQs is often crucial for acceptance within a community. Moreover, non-LGBTQ people can be allies to LGBTQs when standing up against SOGIP expressed by others. The reluctance to offer this support can be seen as a form of subtle SOGIP (Fingerhut, 2011; Poteat, 2015; Poteat \& Vecho, 2016; see also Dovidio et al., 2016).

Relatedly, people scoring high on subtle prejudice tend to justify their potentially biased attitudes or behaviors on nonprejudicial grounds and are less likely to show such prejudiced attitudes or behaviors when justifications are not possible (Dovidio \& Gaertner, 2004). This latter notion is well-illustrated in the research by Morrison and Morrison (2003, 2011). They focused on modern sexual orientation prejudice (e.g., the belief that sexual minorities are too demanding in their search for equal rights or that discrimination based on sexual orientation is no longer a problem; (cf. McConahay, 1986) and demonstrated that people who scored high on modern prejudice kept physical distance from an openly gay or lesbian person when they could justify this behavior on nonbiased grounds. More specifically, participants could choose in which room they would watch a movie. An openly gay or lesbian confederate was already present in one of the rooms, and would watch the movie in that room. When the same movie played in both rooms, people 
high in prejudice were more likely to sit in the same room as the gay/lesbian confederate. In this case, they could not justify sitting in a different room than the gay/lesbian confederate. However, when a different movie played in both rooms, people high in prejudice were more likely to choose to sit in the other room than the lesbian/gay confederate. In this situation, they were able to justify their choice to avoid the gay/lesbian confederate with a nonprejudicial reason (i.e., that they would rather watch the other movie).

Importantly, the fact that SOGIP nowadays is more subtle than it was decades ago does not mean that its consequences are less harmful for the target (Barreto $\&$ Ellemers, 2015). One of the reasons for this is the greater uncertainty regarding negative outcomes in life: Is something due to individual characteristics or prejudice (Major, Kaiser, \& McCoy, 2003)? This uncertainty makes targets of subtle prejudice on guard during their daily social interactions. Such a vigilant state is typically accompanied by increased resistance by the blood vessels to blood flow (high total peripheral resistance). This in turn is a maladaptive cardiovascular response pattern, which on the long run relates to negative health outcomes (Derks $\&$ Scheepers, in press).

Apart from its direct effect on the target, subtle prejudice has another negative consequence. Bystanders often do not recognize subtle prejudice and therefore do not take action against it. In fact, research demonstrates that bystanders tend to become more prejudiced after witnessing the expression of subtle sexual orientation prejudice by others (Krolikowski, Rinella, \& Radcliff, 2016). Krolikowski et al. (2016) instructed students to read a scenario where an in-group member or an out-group member expressed blatant SOGIP, subtle SOGIP, or neutral attitudes toward sexual and gender minorities. For example, in the blatant condition, students read statements such as "I believe that the members of the LGBTQ community choose their sexual preference and are responsible for any discrimination they receive" (Krolikowsky et al., 2016, p. 249); in the subtle condition, students read statements such as "I believe that the LGBTQ community often pushes themselves into areas where they are not wanted" (Krolikowsky et al., 2016, p. 249); and in the neutral condition, students read statements such as "I do not have a problem with the LGBTQ community" (Krolikowsky et al., 2016, p. 249). After reading these statements, students in the subtle prejudice condition demonstrated an increase in sexual orientation prejudice, while students in the blatant and control conditions did not. Furthermore, students in the blatant prejudice condition distanced themselves more from the prejudiced person in the scenario than students in the subtle or neutral condition. Thus, while the expression of blatant prejudice leads to rejecting the prejudiced person, the expression of subtle prejudice does not lead to rejection and even increases prejudice. For all these reasons, we argue that research on SOGIP should include measures of subtle prejudice, and interventions should also target subtle prejudice. In the next section, we provide an overview of 
recent interventions and assess how well these interventions are suited to reduce SOGIP.

\section{Overview of Recent Interventions}

A central theme in the current overview is the shift from blatant to subtle forms of bias, and the implications this has for interventions. Because subtle bias is less explicit than the strong moral convictions that characterize blatant prejudice, and because subtle prejudice is characterized by uncertainty, avoidance (rather than attack), and ambivalence, it is not enough to change people's beliefs in order to reduce subtle SOGIP. Rather, it is important to change people's basic affective responses and behaviors in relation to LGBTQs. In the current section we provide an overview of, and critically analyze, the different interventions that have been developed to reduce SOGIP.

It is important to mention that most research thus far has mainly focused on young people in educational settings, while other groups and settings have received far less research attention (e.g., Bezrukova, Spell, Perry, \& Jehn, 2016). As a consequence, this focus is also reflected in the interventions we describe in this article. We acknowledge this limitation, and we address this more explicitly in the practical recommendations and future directions section. Furthermore, in our aim to broaden the focus, we highlight research with diverse samples whenever possible.

\section{Art and Games}

There is evidence that exposure to artwork (movies, literature) comprising LGBTQ themes at least temporarily reduces prejudice. For example, in a correlational study, Fong Mullin, and Mar (2015) showed that greater exposure to fiction, but not nonfiction, was related to increased gender role egalitarianism and reduced gender role stereotyping, factors that are related to SOGIP. This research shows that reading books (in general, not necessarily related to sexual and/or gender diversity) is related to an acceptance of diversity. The authors suggest that this effect is due to the fact that reading fiction increases perspective-taking (also see below). This may help to explain why other forms of media exposure (such as watching films or television) have been found to increase people's stereotypic attitudes (Fong et al., 2015). Reading may be different to watching films or television in that it may require more perspective-taking, because books stimulate the reader to adopt the view of the protagonist when written from a first-person perspective.

Playing videogames cooperatively with outgroup members has been shown to reduce outgroup prejudice related to race or ethnic origin (e.g., Adachi, Hodson, Willoughby, \& Zanette, 2015; Vang \& Fox, 2014; Velez, Mahood, Ewoldsen, \& 
Moyer-Gusé, 2014). For example, Adachi et al. (2015) showed that when Canadian players took on alien enemies in cooperation with American players, they held much less negative attitudes toward Americans. In this study, Canadian university students played a 12-minute violent video game in which they either cooperated with an ingroup or an outgroup member. After playing together, participants perceived themselves and their outgroup partner as one team and did not discriminate against their outgroup partners (vs. ingroup partners). This highlights the potential for cooperative video games (even violent ones) to serve as prejudice interventions. Thus, cooperating with an outgroup member toward a common goal (i.e., winning a video game) may reduce prejudice, at least in the area of prejudice related to race or ethnicity. However, it is not clear how long these effects last and/or whether cooperatively playing videogames with outgroup members is also effective in reducing SOGIP.

Research indicates that games that increase perspective taking can reduce SOGIP (Hillman \& Martin, 2002; Hodson, Choma, \& Costello, 2013). In the studies by Hillman and Martin (2002) and Hodson et al. (2013), university students were, as part of a course, randomly assigned to a condition in which they played a game in small groups or to a condition in which they listened to a lecture on discrimination of sexual minorities. In the game condition, participants had to imagine living on a different planet where they faced social hardships similar to those experienced by LGBTQs. For example, they could only reproduce via artificial insemination, they were not allowed to publicly display affection, and failure to adhere to these "rules" resulted in punishment. Students were instructed to imagine how they would feel, act and behave in this situation and discuss this within their group. After this exercise, a plenary discussion followed, where the teacher explained that these imagined hardships were similar to what sexual minorities experience in their lives. Participants in the game condition showed stronger reductions in SOGIP compared to participants in the control condition. Importantly, the reduction of SOGIP was mediated by increased perspective-taking. Thus, exposure to art-works or actively playing games involving cooperation or perspective taking have the potential to reduce SOGIP. However, more research is needed to address the underlying mechanisms, and measure the duration of these effects.

\section{Knowledge Transfer: Education and Diversity Training}

Most current interventions are focused on educating people about SOGIP. These interventions aim to raise awareness regarding the stigma and negative treatment that is experienced by LGBTQs and the (unconscious) biases that many people hold. This has proven to be effective in some instances. For example, in a study on increasing knowledge about transgenderism (Walters \& Rehma, 2013) university students either did (experimental condition) or did not (control condition) 
watch a movie featuring children who are transgendered and showing the effect that their expressed atypical gender identity had on their family life. Results indicated that watching the movies did indeed increase participants' knowledge about transgenderism. This effect was particularly strong for participants who had watched a longer version of the movie. Similar interventions have proven to be successful for decreasing SOGIP more generally, and for increasing awareness about heterosexual privilege (Case, Hansley, \& Anderson, 2014). Together, these obervations suggest that presenting LGBTQ relevant information may suffice to reduce SOGIP.

However, other research suggests that providing information and raising awareness by itself may not be sufficient to reduce SOGIP in a sustainable way (Felten et al., 2015). For example, Case and Stewart (2010) found that although diversity courses increased people's awareness of heterosexual privilege, it did not reduce their SOGIP in comparison to a control condition. Moreover, Hubbard et al. (2013) demonstrated that giving people information about LGBTQ topics did not increase their likelihood to stand-up against prejudicial expressions by others. Deese and Dawson (2013), furthermore, showed that when people watched informational videos about the biological underpinnings of same-sex attractions and differences in rights for heterosexuals and homosexuals, they showed more SOGIP than people who did not watch these videos. Finally, there is mixed evidence with regard to whether certain ingredients of LGBTQ education, like discussing biological factors, help or hinder in reducing SOGIP (Felten et al., 2015; Hegarty, 2010). For example, Hegarty (2010) showed that not providing information about biological determinants of sexual orientation in a 10-week course on LGBTQ psychology, significantly reduced sexual orientation prejudice compared to a baseline measure at the beginning of the course.

These findings resonate with a recent meta-analysis conducted by Bezrukova et al. (2016). They investigated 260 independent participant samples to determine whether, when and for whom diversity training programs are effective in producing their intended outcomes. Although diversity training in general seemed to be effective in increasing positive evaluations of the trainers and/or training and in increasing knowledge about diversity, it was less successful in changing attitudes and behaviors. This is unfortunate, given that the latter outcomes are among the most important in reducing prejudice. Although there are many interesting conclusions to be drawn from this research, especially relevant for the current overview is that awareness-based training was less effective than other types of diversity training (e.g., skills development). Important to note is that the metaanalysis by Bezrukova et al. (2016) was conducted on a variety of diversity training that was not focused exlusively on SOGIP reduction, thus, it is not clear to what extent these findings can be translated directly to the effectiveness of diversity training that specifically targets SOGIP. 


\section{Perspective Taking}

The research described above demonstrates that merely transferring knowledge through education and training might not be sufficient in order to reduce SOGIP. Tompkins, Livesay, Shields, Talbot, and Hillman (2014) identified a factor that might be crucial to translate knowledge and awareness into reduced prejudice: Perspective taking (see also Felten et al., 2015). More specifically, Tompkins et al. (2014) addressed the influence of education versus humanization (i.e., empathizing) on the reduction of prejudice toward people who are transgendered. Results indicated that humanization significantly reduced prejudice and increased contact intentions in comparison to education, which did not result in notable changes. This illustrates the promise of perspective-taking as a means to reduce SOGIP.

Perspective taking interventions aim to reduce prejudice by encouraging people to imagine the world from the vantage point of a stigmatized group (Galinsky $\&$ Moskowitz, 2000). In a recent field experiment in which canvassers went doorto-door encouraging voters to actively take the perspective of people who are transgendered, Broockman and Kalla (2016) showed that the intervention successfully reduced transphobia for 3 months. Thus, interventions that increase perspective-taking seem to be promising avenues for durably reducing SOGIP.

\section{Contact Interventions}

One particularly common method for reducing prejudice against a variety of minority groups are contact interventions where (young) people interact with members of a stigmatized group (e.g., Allport, 1954; Pettigrew \& Tropp, 2006; Smith, Axelton, \& Saucier, 2009). The rationale behind this type of intervention is that contact provides interacting parties with unique information about one another, which would result in more positive judgments because the negative inferences based on group membership no longer play a role. Indeed, research suggests that the more contact people have with LGBTQs, the less prejudiced they are toward them (Burke et al., 2015; Cunningham \& Melton, 2013; Earnshaw et al., 2016; Smith et al., 2009; Walters \& Rehma, 2013).

A typical example of a contact intervention is the study by Walch et al. (2012). Students enrolled in a course on human sexuality received a lecture on transgenderism, as well as a panel presentation by four transgendered individuals. The order in which the students followed the lecture and panel presentation was varied: half of the participants received the panel presentation first and then the lecture 1 week later; for the other half this was the other way around. Transphobia was measured before and after the lecture and panel presentation. Results revealed that both the lecture and panel presentation reduced transphobia, but that the panel presentation had the biggest impact. That is, a lecture 1 week after the panel presentation did not further reduce transphobia, while the biggest decrease in 
transphobia was observed directly following the panel presentation. Importantly, these effects were sustained for weeks after the intervention. This shows the power of direct contact with people who are transgendered on reducing transphobia (see for a similar demonstration in Hungaria: Orosz, Banki, Bothel, Toth-Kiraly, \& Tropp, 2016).

Merely imagining contact with an out-group member also has the potential to reduce prejudice and improve behaviors toward the group (Crisp \& Turner, 2009; Miles \& Crisp, 2014). Turner, Crisp, and Lambert (2007), for example, demonstrated that for male heterosexual participants spending a few minutes imagining a positive interaction with a homosexual man improved their attitudes toward gay men in general because it reduced anxiety. However, recently, the effectiveness and replicability of imagined contact have been debated and subsequent research found that imagined contact worked better for people who also had more actual contact (Hoffarth \& Hodson, 2016). Thus, more research is needed to determine whether imagined contact is indeed effective, and whether it works as well as actual contact.

At the same time, other research did not obtain a positive effect of contact on the reduction of SOGIP (Cotten-Huston \& Waite, 1999). On the contrary, there are even indications that certain activities during contact interventions can backfire and increase sexual orientation prejudice (Felten, Emmen, \& Keuzenkamp, 2015). For example, it is possible for people to become more prejudiced after hearing negative remarks about LGBTQs from others in their group (Walker, Sinclair, \& MacArthur, 2015). This is likely to happen in contact interventions where participants are invited to engage in an open discussion with LGBTQ-people, where both positive and negative remarks are welcomed. This may be particularly consequential for subtle SOGIP, because people do not tend to realize the prejudiced nature of these kind of remarks and are more likely to conform to them (Krolikowski et al., 2016). So an important question that needs to be addressed is what the requirements are for a successful contact intervention, and how the effectiveness of existing interventions can be increased.

It is important to note in this context that "contact intervention" is an umbrella term, and that specific contact interventions often combine multiple intervention techniques. Some techniques may be more successful in reducing SOGIP than others, while others may even be counterproductive. According to a recent review (Felten et al., 2015), the key ingredient to a successful contact intervention seems to be that it invokes empathy. Empathy can be increased through the sharing of personal experiences, such as LGBTQ people sharing their coming-out story and the hardships they experienced during this period. This is similar to intervention techniques aimed at increasing perspective taking. So, although contact interventions have great potential to reduce SOGIP, their effectiveness seems to depend on the specific activities that are being employed during this contact. 
In addition to the specific activities employed, other factors that influence the effectiveness of contact interventions are adherence to the intervention program, the skills of the trainers, and contextual barriers (Vanwesenbeeck, Westeneng, De Boer, Reinders, \& Van Zorge, 2015). An intervention program, such as a contact intervention, has to be followed strictly in order to reach the intended positive effects. However, in reality, program delivery in real settings is often not as intended. For example, sometimes lessons are shortened or adapted. Practical issues may also play a role here, such as unexpected room changes, equipment failure, and inefficient schedules. The skills of the trainers who deliver the intervention are essential to intervention effectiveness (Vanwesenbeeck et al., 2015). Being motivated, confident in addressing sensitive topics, and being able to employ the right teaching techniques are crucial. However, many real-life contact interventions to reduce SOGIP are provided by voluntary trainers, who-in general-are passionate volunteers rather than professional educators. Furthermore, more systematic, experimental and longitudinal research is necessary to support the proposed causal relationship between contact and prejudice reduction, as well as the underlying factors. Empathy and perspective taking seem to be promising mechanisms that can potentially, at least partially, explain positive effects of contact interventions.

\section{Developing Alliances}

The ultimate intervention to reduce SOGIP may be developing alliances, where majority people (e.g., heterosexual, cis-gendered people) become strong supporters of sexual and gender minorities (Herek, 2007). A number of factors predict active bystander engagement against homophobic behavior, like gender (i.e., girls are more likely to take action than boys), leadership, courage, altruism, justice sensitivity and the number of LGBTQ friends one has (Fingerhut, 2011; Poteat \& Vecho, 2016). Knowledge of these factors may prove useful for developing specific interventions (e.g., focusing on people less likely to demonstrate positive behaviors, such as males, or on increasing justice sensitivity) to stimulate developing alliances. Not much research exists on how to develop alliances, and this is indeed an important area for future research.

However, promising initivatives in this direction are the so-called "Gay Straight Alliances" (GSA; sometimes also referred to as "Gender Sexuality Alliance"; see e.g., www.gsanetwork.org). GSA's are student-run clubs in schools that bring together majority and minority students to support each other, to create a safe place to socialize, and to offer a platform to fight for the reduction of SOGIP. Several studies indicate positive effects for LGBTQ youth of having a GSA at their school (Heck, Flentje, \& Cochran, 2011; Toomey, McGuire, \& Russell, 2012; Walls, Kane, \& Wisneki, 2010). For example, Walls et al. (2010) demonstrated that sexual minority youth have more positive school experiences when a 
GSA is present at their school, regardless of whether they are active members or not. However, there is relatively little empirical research on the effectiveness of GSA's in terms of reducing SOGIP. Furthermore, it is not clear whether schools that have GSA's had a more positive climate toward sexual and gender minorities to begin with, or whether this positive climate was a consequence of the GSA. Thus, again, experimental and longitudinal research is needed to assess whether starting a GSA has positive and lasting effects on SOGIP reduction.

Importantly, alliances do not only have positive consequences for minority members, but also for allies. Rostosky, Black, Riggle, and Rosenkrantz (2015) showed that heterosexuals experienced being an ally as very rewarding. Allies, for example, felt good about functioning as a role model. Thus, developing alliances may lead to increased well-being for minority members, as well as majority members who operate as allies. It is important to note here that, in contrast to the interventions discussed above, developing alliances is a structural change that lasts for a long period of time and has therefore the potential to reduce SOGIP in a sustainable way. This potential seems to be supported by a meta-analysis conducted by Bezrukova et al. (2016) who demonstrated that interventions that lasted for a longer period of time and/or were integrated in the curriculum were more succesful.

\section{Conclusions on Existing Interventions}

There are several types of interventions that are currently being employed to target SOGIP. Passive interventions such as watching videos and plays and reading books can sometimes be successful in lowering SOGIP, while more active and immersive interventions (e.g., playing videogames) seem particularly promising. Knowledge transfer and/or sexual diversity training yield mixed effects. Interventions aimed at perspective taking are promising, but relatively few empirical studies has focused on this intervention type. Contact interventions are relatively succesful but their effectiveness depends on several factors. Some activities during contact interventions may even backfire and increase SOGIP. One key factor for success seems to be evoking empathy in participants. The causal relationship between contact and SOGIP reduction needs to be investigated more critically. Finally, the ultimate intervention seems to be developing alliances, where majority members show active behavioral support for minority members. Alliances have the potential for longlasting and meaningful SOGIP reduction, as well as for increased positive behavioral reactions.

However, there are still many questions to be answered. Overall, there is little empirical evidence as to the robustness of intervention effects, contextual factors, the underlying mechanisms and the duration of effects. In the next section, we provide practical recommendations for practitioners and policymakers based on 
the current state of the literature. Furthermore, we make suggestions for future research to fill important gaps in this literature.

\section{Recommendations for Research, Practice, and Policy}

Despite a steady increase in academic interest in SOGIP, more research is needed in order to fully understand and contribute to reducing the negative treatment of LGBTQs. Here, we identify the most glaring gaps in the literature as a potential roadmap for future work in this area. Furthermore, an important goal of this article is to provide practitioners and policymakers with evidence-based guidelines as to how to durably prevent and reduce SOGIP.

\section{Reducing SOGIP in Research, Policy, and Practice}

Although researchers tend to treat sexual orientation prejudice and gender identity prejudice as distinct theoretical phenomena, as discussed above, there is evidence for a strong and partly causal relationship between the two (Lick \& Johnson, 2014; Parrott \& Gallagher, 2008; Stotzer \& Shih, 2012). Therefore, research should at the very least take gender identity prejudice into account when researching sexual orientation prejudice, and vice versa. In addition, we recommend more in-depth studies on the specific relationship between the two. If sexual orientation prejudice indeed has its roots in gender identity prejudice, follow-up research would do well to examine why gender nonconformity is such a threat to people. As one possible direction, based on recent research demonstrating a link between resistance to change and SOGIP (Van der Toorn et al., 2017), we hypothesize that SOGIP may be rooted in psychological needs to maintain the (heteronormative) status quo.

Furthermore, an interesting avenue for intervention research would be to investigate whether decreasing people's focus on gender differences and gender roles may also indirectly decrease SOGIP. There is already some preliminary evidence from Sweden that this may indeed be the case. As one of the frontrunners with regards to gender equality, Sweden recently implemented gender-neutral practices in some schools. In these schools, gender-neutral pronouns are used, traditional gender roles and family structures are counteracted through adapted songs and stories, and behaviors traditionally directed at a specific gender are avoided (e.g., commenting on girls' appearances; Shutts, Kenward, Falk, Ivegran, \& Fawcett, 2017). Focusing on several dimensions, Shutts et al. (2017) examined how children in these gender-neutral schools fared compared to children in "typical" schools. Results suggested that children in the gender-neutral schools were more interested in playing with unfamiliar opposite-gender children and scored lower on gender stereotyping than children in "typical" schools. However, sample sizes in this study were small and participating schools probably differed in more aspects 
than their gender policies alone. Thus, more research is needed to investigate the robustness of positive outcomes of gender-neutrality on gender identity prejudice, and to assess whether gender neutrality may also reduce sexual orientation bias.

Despite these limitations, these findings may be relevant for policymakers at both the local and national level. Implementing gender-neutral policies in schools, as well as in local and national governments, organizations and institutions seems feasible. There are already some examples: national policies to provide genderaware education (e.g., in Sweden), (plans to implement) gender-neutral toilets in government buildings (e.g., in Belgium, Scotland, and Tokyo, as well as multiple cities in the Netherlands); initiatives to address travelers in public transport with "dear travelers" rather than "ladies and gentlemen" (e.g., the Netherlands); clothing brands removing gender labels from clothing and/or creating gender-neutral clothing lines (e.g., in the United Kingdom and the Netherlands).

Practice and policy aimed at gender neutrality also serves to increase the inclusion of people who are transgendered, an underrepresented group in (research on) SOGIP interventions (but see Broockman \& Kalla, 2016; Walters \& Rehma, 2013, for exceptions). As people who are transgendered can be perceived as violating gender norms, they may be especially vulnerable to prejudice that is based in gender role violation, and may benefit especially from gender-neutral policies that reduce SOGIP.

\section{Focus on Both Blatant and Subtle SOGIP}

As outlined in the beginning of this article, SOGIP can be expressed in blatant and subtle ways. However, little research has been conducted to determine how different interventions may impact the different forms of SOGIP, and research often focuses on one aspect of SOGIP only. One might hypothesize that more passive intervention methods, such as information transfer, or exposure to art/literature might be a first step to "unfreeze" the convictions of people high in blatant prejudice. For people high in blatant SOGIP, more immersive interventions involving actual contact may be too threatening at first, leading to defensive responses and making these interventions work counter-productive in the end. Indeed, as explained above, under some circumstances contact may even do more harm than good. However, for people high in the more subtle forms of SOGIP, more immersive interventions, based on actual contact with the aim to further increase empathy, may be particularly functional for further reducing the uncertainties during actual intergroup interactions that are so typical for those high in subtle prejudice (Shelton, Richeson, $\&$ Vorauer, 2006). Although people high in subtle prejudice may appear to have the best intentions and seem unprejudiced in their verbal expressions, their more subtle biases may still leak through in their nonverbal bahaviors. Contact interventions making use of perspective-taking may be particularly useful to overcome this "last hurdle" and to take away uncertainties when interacting with LGBTQs. 
Moreover, we recommend that research assessing the effectiveness of a certain intervention aimed at reducing (a certain aspect of) SOGIP measures both blatant and subtle aspects of SOGIP. Table 1 gives examples of measures that can be included. We recommend that researchers and practitioners include several important aspects of SOGIP: blatant and subtle rejection of sexual and gender minorities (e.g., Buck et al., 2013; Herek, 1997), blatant and subtle rejection of same-sex couples (e.g., Monto \& Supinski, 2014), blatant and subtle rejection of gender nonconformity (e.g., Hill \& Willoughby, 2005; Oransky \& Fisher, 2009) and blatant and subtle prejudice against bisexuals (e.g., Eliason, 1997). Combining these aspects should give a more representative and generalizable overview of the effect of a certain intervention on the different facets of SOGIP.

\section{Focus on Behavior}

Effective interventions should not only reduce prejudicial attitudes, but also increase positive behaviors toward targeted minority groups. In other words, the ultimate measure of the effectiveness of an intervention may be the extent to which an intervention is successful in the development of alliances. However, actual behavioral outcomes have largely been overlooked in theory and practice. We therefore recommend that future research measures allied behaviors, in addition to more traditional forms of prejudice. One way of doing so would be to examine real-life contact interventions, and evaluate how participants behave toward LGBTQ people. This would, for example, be possible in lab settings where people first take part in an intervention and subsequently interact with an LGBTQ person. Video recordings could be used to evaluate the positivity of the interaction through tallying the positive and negative behaviors that participants demonstrate. Policymakers can keep track of, acknowledge and/or reward, positive efforts to reduce SOGIP in society. Those working to counteract prejudice often do so of their own volition, through bottom-up, grassroots initiatives. Local and national governments can facilitate these efforts by supporting them financially, or by providing resources such as community spaces or media attention.

\section{Focus on Majority and Minority Members}

Most research focuses on prejudice reduction in holders of SOGIP with a focus on majority members. However, SOGIP has shifted from blatant to more subtle forms that can be hard to detect when merely focusing on holders of prejudicial beliefs (such as people who are heterosexual and/or cisgendered). As explained above, people are often not aware of (or willing to acknowledge) their own prejudicial beliefs. Therefore, it is important to also assess the experiences of targets of SOGIP (e.g., LGBTQ people). This may be particularly relevant when assessing interventions where majority members interact with one or more 
minority members (e.g., classroom intervention settings where students receive a training from an LGBTQ person). In these settings, it may be worthwhile to not only measure SOGIP in those who participate in the training (i.e., students), but also assess how the LGBTQ-trainer experienced the contact with participants. The same holds for other types of interventions where majority and minority members interact, such as playing (video) games together. In these instances, it is advisable to assess the experiences of both parties, rather than focusing on majority members alone. Policymakers can also play a role in this regard, for example, by actively following up with minority members in order to assess how they evaluate the (impact of) efforts to reduce SOGIP. For example, when organizations implement gender-neutral bathrooms in their buildings, they may want to invite diverse employees to reflect on how this change has impacted them. Successful interventions should not only decrease prejudiced attitudes and behaviors in holders of prejudice, but should also increase positive interactions and experiences for both majority and minority members alike.

\section{Define the Effectiveness of Existing Interventions}

Interventions are often derived from a combination of common sense and a view that "there's no harm in trying," but few are evaluated to assess whether they produce measurable effects. In fact, there are examples of interventions that ironically achieve opposite effects from what was intended (Felten et al., 2015). A study by Legault, Gutsell, and Inzlicht (2011), for example, demonstrated that efforts to reduce prejudice by enforcing antiprejudice standards can result in more prejudice than not intervening at all. In this research, university students received either a brochure that focused on emphasizing choice and explaining why prejudice reduction was important (the autonomy condition); a brochure that stressed social norms to be nonprejudiced (the controlling condition); or no brochure (the control condition). Results indicated that participants in the controlling condition experienced less motivation to be nonprejudiced than participants in the other conditions, presumably because the intervention threatened their sense of autonomy and led to reactance. Examples such as these stress the need for a scientific, evidence-based, approach to the design, assessment, and broad implementation of SOGIP interventions (see Moss-Racusin et al., 2014 for similar suggestions with regard to scientific diversity interventions to reduce gender bias in academia).

Ideally, practitioners that conduct intervention programs would collaborate with independent researchers in assessing the effectiveness of these programs. It is important that researchers have no stake in the outcomes of the assessment in order to avoid confirmation bias. While researchers could develop hypotheses, create research instruments and conduct data analyses, practitioners could distribute and collect research instruments among participants in the intervention. The ideal 
research design from a theoretical standpoint would be one where (groups of) participants are, after filling out a baseline measure, randomly assigned to either an intervention or a no-intervention condition (randomized controlled trial), followed by repeated measures in time.

Selection bias. There are several types of selection bias that are problematic in many of the studies that have been discussed thus far. For example, in correlational contact studies, it is often not clear whether contact with minority members reduces prejudice, or whether less prejudiced people are more likely to seek contact with minority members. In fact, in research by Loehr, Doan, and Miller (2015), selection effects completely explained differences in SOGIP between those who did, and those who did not, have contact with minority members. These researchers investigated heterosexuals' reactions to a vignette depicting a gay or lesbian couple. Participants indicated the extent to which they granted the couple formal rights (e.g., partnership benefits) and informal privileges (e.g., public displays of affection), and reported demographic background information such as sex and age, as well as whether or not they had a friend or relative who was LGBTQ. After controlling for selection effects through propensity score matching (i.e., accounting for the observable differences between the types of people more likely to have contact vs. the types of people more likely not to have contact), the effect of contact on formal rights and informal privileges disappeared. Thus, mere contact may not be as successful in reducing SOGIP as is suggested by correlational research (Loehr et al., 2015). Still, experimental research assessing the effect of contact on the reduction of other types of prejudice give grounds for hope. Page-Gould, Mendoza-Denton, and Tropp (2008), for example, demonstrated that the induction of cross-group friendship between Latinas and Whites reduced the release of stress hormones and increased the initiation of new intergroup interactions.

Especially in field settings such as schools and organizations, the ideal of randomized controlled trials can be difficult to achieve. Whether or not certain groups, classes, departments or individuals will receive an intervention program is often not random, but, for example, determined by school boards or higher management. And even if random assignment to condition can be established, there is another form of selection bias that results from voluntary participation; Highly prejudiced people may, namely, decide to refrain from participating in studies and training programs that are obviously aimed at reducing SOGIP.

This bias could be reduced by not informing participants of the exact topic of the study or program in advance. However, even then, high prejudiced participants may be more likely to drop out of the study or program than lower prejudiced participants, which would be especially problematic with repeated measures over time. These issues may be circumvented by introducing obligatory intervention programs (which have the added benefit of being more effective than voluntary 
programs; Bezrukova et al., 2016) and by designing interventions that are (or seem to be) less specifically aimed at reducing SOGIP. Missing value analysis can, furthermore, be conducted to determine whether any remaining attrition occurred at random or not (see Graham, 2009 for an overview of different analytical strategies for missing data analysis).

This is one area where policymakers could exert their influence. For instance, by making SOGIP intervention practices obligatory in all educational and business settings and by investing in interventions that are more general in nature (i.e., aimed at increasing certain desirable skills or outcomes). One example of the latter may be interventions aimed at increasing empathy or perspective taking (e.g., Hillman \& Martin, 2002). These kinds of interventions may be equally attractive to schools and organizations with varying levels of LGBTQ-friendly (or unfriendly) climates.

Assessing the effectiveness of existing interventions is especially important because real-life interventions are often provided in different settings than those reported in scientific outlets. For example, there are countless existing intervention programs where high school students interact with LGBTQ people, but virtually none of these programs has been subjected to rigorous empirical testing (for an exception, see Orosz et al., 2016).

Practical obstacles. Obviously, there may be practical obstacles in the implementation of such assessment. Given that many interventions target young people (i.e., <16 years), active parental consent is often necessary before data collection can commence. This may be difficult to achieve for researchers but less so for practitioners. It has been shown that active parental consent is more likely to be provided when the intervention is integrated in the curriculum. For example, Pokorny, Jason, Schoeny, Townsend, and Curie (2001) demonstrated that when consent packages were sent together with a report card that needed to be signed by a parent, the response rate was relatively high $(82 \%)$. In contrast, when consent packages were mailed directly to students' homes, with a stamped postcard to be mailed to the research team, reponse rates were much lower (33\%). Thus, cooperation between practioners and researchers may be essential to overcome practical obstacles. Related issues are that parents may be less likely to provide consent for their children to participate in research on sensitive topics, and/or that high prejudiced parents may be less likely to provide consent.

Local governments could help in overcoming such practical obstacles by supporting initiatives to reduce SOGIP in their communities. For example, local policymakers can organize events where scientists and pracitioners meet, thereby notifying practitioners of the interventions or measures that are available to them. This may stimulate cooperation with an intervention program, without reducing 
feelings of autonomy among the recipients (which may be counterproductive, see e.g., Legault et al., 2011).

\section{Train the Trainers}

As briefly noted above, the actual people carrying out intervention programs (e.g., trainers conducting class-room interventions) should be carefully trained themselves to be able to deliver the training consistently, professionally, and with sufficient eye for detail when it comes to the crucial ingredients of the intervention (e.g., Vanwesenbeeck et al., 2015). Special attention should be paid to managing difficult groups and the conflicts that may arise during the intervention itself. Awkward intergroup interactions often arise through an interplay of the behavior of perpetrators and targets of prejudice (Shelton et al., 2006), and the development of prejudice during such interactions often takes the form of a selffulfilling prophecy. Trainers should be trained in how to break such a chain of events and should be able to critically reflect upon their own behavior and the possibility that they may have internalized prejudice themselves. In relation to this, trainers should be aware of their own possible prejudice toward majority members or subgroups within the LGBTQ population. Researchers should identify crucial elements in intervention delivery, in order to develop a "train the trainers" program that supports a validated intervention program. Once again, policymakers (e.g., local and national governments) can play a key role here by supporting initiatives for training trainers. Furthermore, policymakers could mandate the use and prioritize (financial) support of intervention and "train the trainers" programs that are evidence-based.

\section{Combining Techniques to Improve Existing Interventions}

In field research, interventions are often evaluated as a whole without the ability to pinpoint the active ingredients responsible for effects. For example, existing contact interventions may be a mix of different elements, and some of these elements may be more effective than others. When evaluating the effectiveness of such interventions, it is not possible to isolate the specific elements that drive their effects (or that explain the absence of effects). Lab research, on the other hand, does allow for the systematic study of a particular factor. For example, it is possible to pit certain types of intervention activities against each other, and see which of them is most effective. Both types of research to date have neglected possibilities of studying the combination of different intervention techniques. We recommend a combination of methods so that active ingredients of different techniques are first distilled (e.g., in the lab) and attention is then paid to how they may best work together (e.g., in the field). 
Based on the literature reviewed above, we conclude that elements that have most potential for success are those that evoke empathy and perspective taking, while less effective strategies seem to be focused purely on knowledge transfer. Practitioners could benefit from this knowledge by critically evaluating the content of their existing interventions. Furthermore, it is also advisable to assess the effectiveness of changes made in existing intervention programs by comparing the effectiveness of pre- and postchange interventions.

\section{Mechanisms and Boundary Conditions}

More understanding is needed of the mechanisms through which interventions work. Our literature review suggests that empathy may play an important role, as positive effects of several interventions seem to particularly occur when empathy is induced. Hence, the exact role of empathy should be examined. For example, if contact effects are indeed contingent on whether the contact generates empathy or not, this might lead to the conclusion that actual interpersonal contact may not be necessary to reduce SOGIP. Instead, other interventions, such as perspective-taking training, may be sufficient. This is relevant for policymakers and practitioners, because contact interventions can be very expensive (in terms of time and money) or difficult to implement on a large scale. It would be most efficient to implement interventions that are low in costs, but high in effectiveness. There are already some promising interventions that are easier to implement than " real" contact interventions. Examples include playing online games together with an outgroup member or, watching movies/plays that evoke empathy (see above). A particularly promising idea would be to develop virual reality simulations of intergroup contact, which can be standardized, cost-efficient, and easily widely implemented (e.g., in school settings) to reduce SOGIP (Yee \& Bailenson, 2006).

More research is also needed to identify the specific boundary conditions of effects. When, for whom, and under which circumstances do interventions work? With regard to contact interventions, we know that effects can be facilitated by certain factors (e.g., the presence of interdependence and institutional support) but are not dependent on these conditions being in place (Pettigrew \& Tropp, 2006). Furthermore, as described above, contextual factors such as program adherence and the quality of the trainers, seem to be crucial for effective interventions (Vanwesenbeeck et al., 2015). It seems especially important to investigate boundary effects of promising interventions of which the robustness is not yet clear, such as exercises to increase perspective-taking (e.g., Hilmann \& Martin, 2002; Hodson et al., 2013).

Two potential boundary conditions seem to warrant additional research attention: the longevity of effects (i.e., the extent to which an intervention produces longer-term effects) and the generalizability of effects to different populations. For example, does playing videogames cooperatively also lead to reduced prejudice in 
children, adolescents, elderly people, and employees, or is it only (or especially) a successful intervention to reduce prejudice in students (e.g., Adachi et al., 2015)?

\section{Diverse Samples}

Little work has systematically investigated whether effects are dependent on the specific sample under study. Although theory building is simplified by the generalizability of effects to a variety of populations, it is practically important that we can be sure that an intervention works in the particular context to which it is applied.

This may be particularly relevant because most interventions in real-life are targeted at children and adolescents. However, an overwhelming number of participant samples consist of college students participating in studies for class credit. There may be important differences between the youngsters who partake in actual interventions and highly-educated university students from industrialized and democratic countries (so-called WEIRD samples; Jones, 2010). There may even be larger differences between college students and other demographic groups (e.g., elderly people, non-Western samples). In order to counteract this tendency to focus on (college) students, in our literature review we have also highlighted noncollege samples and field studies (e.g., Broockman \& Kalla, 2016; Buijs et al., 2011; Dessel, 2010; Orosz et al., 2016). Still, it may very well be that less educated participants living in different systems in other parts of the world exhibit different attitudes that are expressed in different ways. For one thing, the preponderance of subtle over blatant forms of prejudice may not be as pronounced in more diverse samples. Future research should study more diverse samples.

Another practical recommendation would be for researchers to use the knowledge and practical experience of trainers who provide such interventions. For example, the largest Dutch LGBTQ-interest organization, COC Nederland (www.coc.nl) includes many trained LGBTQ-guest lecturers. These guest lecturers have ample experience in dealing with SOGIP in real-life settings and therefore have important insights into how groups with different characteristics react to certain elements in interventions. For example, anecdotical evidence from conversations with LGBTQ guest lecturers shows that sharing coming-out stories often has very positive effects on high school students. This corroborates the findings about the positive effects of triggering empathy, described above.

Furthermore, anecdotal evidence from LGBTQ guest lecturers from the COC intervention program at Dutch high schools, ${ }^{4}$ suggests that relativey highly educated students seem to be more timid and less responsive than relatively

\footnotetext{
${ }^{4}$ In some countries, such as the Netherlands, students are divided into classes based on educational level. As a consequence, some classes contain relatively highly educated students, while other classes contain relatively low educated students.
} 
low-educated students. This may be be an indicator that subtle prejudice is relatively high in these types of classes. Furthermore, larger groups or groups with a majority of boys seem to be more resilient against attitude change and prejudice reduction than smaller groups or groups with a majority of girls (Cramwinckel, Scheepers, \& Wilderjans, in prep). Rigorous empirical research is needed to examine whether these experiences by LGBTQ guest lecturers are supported by empirical evidence. If so, then this would have important consequences for the generalizability of empirical research performed on university student samples to other samples (i.e., lower educated people).

\section{Prejudice Reduction at a Community Level}

Given the fact that few prejudice reduction strategies have been formally evaluated in the field, we must extrapolate well beyond the available data in order to make recommendations to governments and institutions in terms of the interventions and policy changes they might undertake to facilitate the reduction of SOGP at a community level. Based on our literature review, we can speculate, however, that strategies that evoke empathy and perspective-taking may be a promising course of action. Media campaigns, for example, may feature the personal experiences of individuals that the public can relate to or holds in esteem (such as famous actors, singers, or other public figures). To go beyond awareness raising, however, these activities should also provide explicit suggestions as to how to make a positive behavior change. Administrations may fund local and national initiatives that bring a variety of sexual orientations, gender identities and gender expressions into the mainstream (e.g., by backing films or tv shows featuring LGBTQ lives). This is especially important because commercial organizations are often uninterested in funding these kinds of initiatives (or may decide to cancel them), even when these initiatives have considerable impact on minority members' lives.

\section{Conclusion}

So where does this leave us? There are many types of interventions that are currently being employed to target SOGIP. Some of these interventions seem to be more effective than others. Based on the current literature, we argue that particularly promising interventions are those aimed at evoking empathy and perspective taking, such as playing games where one takes the perspective of minority members or contact interventions where minority members share personal experiences. Also, interventions aimed at developing alliances hold great promise since they not only have the potential to reduce SOGIP in a longlasting way, but also to increase positive behaviors aimed at supporting minority members.

However, there are several issues to be improved. Overall, there is little empirical evidence about the robustness of intervention effects, the underlying 
mechanisms, the duration of the effects and boundary conditions of interventions. More specifically, researchers should focus on relevant aspects of SOGIP; different expressions of prejudice (i.e., blatant and subtle); actual behavior toward sexual and gender minorities; and on perpetrators and majority members as well as targets of prejudice. Researchers and practitioners should join forces to overcome practical and theoretical obstacles in evaluating the effectiveness of exising interventions. Lab research can provide more insight into critical elements of interventions while field studies can demonstrate how the combination of several elements influences SOGIP reduction. In all of these steps, policymakers can play a vital role by supporting initiatives that test, improve, implement and distribute intervention programs, as well as by bringing together researchers and practitioners. Finally, we would like to urge researchers, policymakers and practitioners to work together to increase the effectiveness of interventions, in order to reduce sexual orientationand gender identity prejudice in a longlasting and meaningful way.

\section{References}

Adachi, P. J. C., Hodson, G., Zanette, S., \& Willoughby, T. (2015). Brothers and sisters in arms: Intergroup cooperation in a violent shooter game can reduce intergroup bias. Psychology of Violence, 5, 455-462.

Allport, G. W. (1954). The nature of prejudice. Cambridge: Perseus Books.

Barreto, M., \& Ellemers, N. (2015). Detecting and experiencing prejudice: New answers to old questions. Advances in Experimental Social Psychology, 52, 139-219.

Bezrukova, K., Spell, C. S., Perry, J., \& Jehn, K. A. (2016). A meta-analytical integration of 40 years of research on diversity training. Psychological Bulletin, 142, 1227-1274.

Bosson, J. K., Weaver, J. R., Caswell, T. A., \& Burnaford, R. M. (2011). Gender threats and men's antigay behaviors: The harmful effects of asserting heterosexuality. Group Processes \& Intergroup Relations, 15(4), 471-486. https://doi.org/10.1177/1368430211432893

Broockman, D., \& Kalla, J. (2016). Durably reducing transphobia: A field experiment on door-to-door canvassing. Science, 352, 220-224.

Buck, D. M., Plant, E. A., Ratcliff, J., Zielaskowski, K., \& Boerne, P. (2013). Concern over the misidentification of sexual orientation: Social contagion and the avoidance of sexual minorities. Journal of Personality and Social Psychology, 105, 941-960.

Buijs, L., Hekma, G., \& Duyvendak, J. W. (2011). 'As long as they keep away from me': The paradox of antigay violence in a gay-friendly country. Sexualities, 14, 632-652.

Burke, S. E., Dovidio, J. F., Przedworski, J. M., Hardeman, R. R., Perry, S. P., Phelan, S. M., Nelson, D. B., Burgess, D. J., Yeazel, M. W., \& van Ryn, M. (2015). Do contact and empathy mitigate bias against gay and lesbian people among heterosexual medical students? A report from medical student CHANGES. Academic Medicine, 90, 645-651.

Case, K. A., Hansley, R., \& Anderson, A. (2014). Reflecting on heterosexual and male privilege: Interventions to raise awareness. Journal of Social Issues, 70, 722-740.

Case, K. A., \& Stewart, B. (2010). Changes in diversity course student prejudice and attitudes toward heterosexual privilege and gay marriage. Teaching of Psychology, 37, 172-177.

CNN (2016, June). Orlando shooting: 49 killed, shooter pledged ISIS allegiance. CNN. Retrieved from the CNN website: http://edition.cnn.com

Chaux, E., \& Léon, M. (2016). Homophobic attitudes and associated factors among adolescents: A comparison of six Latin American countries. Journal of Homosexuality, 63, 1253-1276.

Collier, K. L., Bos, H. M. W., \& Sandfort, T. G. M. (2012). Intergroup contact, attitudes towards homosexuality, and the role of acceptance of gender non-conformity in young adolescents. Journal of Adolescence, 35, 899-907. 
Cotten-Huston, A. L., \& Waite, B. M. (1999). Anti-homosexual attitudes in college students: Predictors and classroom interventions. Journal of Homosexuality, 38, 117-133.

Cramwinckel, F. M., Scheepers, D. T., \& Wilderjans, T. F. (2017). Reducing Modern Sexual Prejudice with LGBT Contact Interventions. (pp. 241-264). Oxford, the United Kingdom: Manuscript in preparation.

Crisp, R. J., \& Turner, R. N. (2009). Can imagined interactions produce positive perceptions? Reducing prejudice through simulated social contact. American Psychological Association, 64, 231-240.

Cunningham, G. B., \& Melton, E. N. (2013). The moderating effects of contact with lesbian and gay friends on the relationships among religious fundamentalism, sexism, and sexual prejudice. Journal of Sex Research, 50(3-4), 401-408. https://doi.org/10.1080/00224499.2011.648029

Deese, M. A., \& Dawson, B. L. (2013). Changing attitudes toward LGBT students: An analysis of an awareness training paradigm aimed at increasing pro-LGBT attitudes. Papers \& Publications: Interdisciplinary Journal of Undergraduate Research, Vol. 2, Article 7. Retrieved from http://digitalcommons.northgeorgia.edu/papersandpubs/vol2/iss $1 / 7$

Derks, B., \& Scheepers, D. (in press). Neural and cardiovascular pathways from stigma to health. In B. Major, J. F. Dovidio, and B. G. Link (Eds.), The handbook of stigma, discrimination and health. Oxford University Press.

Dessel, A. B. (2010). Effects of intergroup dialogue: Public School teachers and sexual orientation prejudice. Small Group Research, 41, 556-592.

Doan, L., Loehr, A., \& Miller, L. R. (2014). Formal rights and informal privileges for same-sex couples: Evidence from a national survey experiment. American Sociological Review, 79, 1172-1195.

Dovidio, J. F., Gaertner, S. L., \& Pearson, A. R. (2016). Aversive racism and contemporary bias. In F. K. Barlow \& C. G. Sibley (Eds.), The Cambridge handbook of the psychology of prejudice.

Dovidio, J. F., \& Gaertner, S. L. (2004). Aversive Racism. Advances in Experimental Social Psychology, $36,1-52$.

Dovidio, J. F., \& Gaertner, S. L. (1998). On the nature of contemporary prejudice: The causes, consequences, and challenges of aversive racism. In J. Eberhardt \& S. T. Fiske (Eds.), Confronting racism: The problem and the response (pp. 1-32). Newbury Park, CA: Sage.

Earnshaw, V. A., Jin, H., Wickersham, J. A., Kamarulzaman, A., John, J., Lim, S. H., \& Altice, F. L. (2016). Stigma toward men who have sex with men among future healthcare providers in Malaysia: Would more interpersonal contact reduce prejudice? AIDS Behavior, 20, 98-106. https://doi.org/10.1007/s10461-015-1168-X

Eisler, R. M., \& Skidmore, J. R. (1987). Masculine gender role stress: Scale development and component factors in the appraisal of stressful situations. Behavior Modification, 11, 123-136.

Eliason, M. J. (1997). The prevalence and nature of biphobia in heterosexual undergraduate students. Archives of Sexual Behavior, 26, 317-326.

Falomir-Pichastor, J. M., \& Mugny, G. (2009). "I'm not gay... I'm a real man!”: Heterosexual men's gender self-esteem and sexual prejudice. Personality and Social Psychology Bulletin, $35,1233-1243$.

FBI (2015, November). Latest Hate Crime Statistics Available: Report Contains Info on Offenses, Victims, and Offenders. The Federal Bureau of Investigation. Retrieved from the FBI website www.fbi.gov on August 11, 2016.

Felten, H., Emmen, M., \& Keuzenkamp, S. (2015). Do the right thing: De plausibiliteit van interventies voor vergroting van acceptatie van homoseksualiteit. (Project number P2565). Movisie. Retrieved from the Movisie website www.movisie.nl

Fingerhut, A. W. (2011). Straight allies: What predicts heterosexuals' alliance with the LGBT community? Journal of Applied Social Psychology, 41, 2230-2248.

Fong, K., Mullin, J. B., \& Mar, R. A. (2015). How exposure to literary genres relates to attitudes toward gender roles and sexual behavior. Psychology of Aesthetics, Creativity, and the Arts, 9, 274-285.

Galinsky, A. D., \& Moskowitz, G. B. (2000). Perspective-taking: Decreasing stereotype expression, stereotype accessibility, and in-group favoritism. Journal of Personality and Social Psychology, $78,708-724$. 
Glick, P., Gangl, C., Gibb, S., Klumpner, S., \& Weinberg, E. (2007). Defensive reactions to masculinity threat: More negative affect toward effeminate (but not masculine) gay men. Sex Roles, 57, 55-59. https://doi.org/10.1007/s11199-007-9195-3

Graham, J. W. (2009). Missing data analysis: Making it work in the real world. Annual Review of Psychology, 60, 549-576. https://doi.org/10.1146/annurev.psych.58.110405.085530

Haas, A. P., Eliason, M., May, V. M., Mathy, R. M., Cochran, S. D., D’Augelli, A. R., Silverman, M. M., Fisher, P. W., Hughes, T., Rosario, M., Russell, S. T., Malley, E., Reed, J., Litts, D. A., Haller, E., Sell, R. L., Remafedi, G., Bradford, J., Beautrais, A. L., Brown, G. K., Diamond, G. M., Friedman, M. S., Garofalo, R., Turner, M. S., Hollibaugh, A., \& Clayton, P. J. (2010) Suicide and suicide risk in lesbian, gay, bisexual, and transgender populations: Review and recommendations. Journal of Homosexuality, 58(1), 10-51. https://doi.org/10.1080/00918369.2011.534038

Haddock, G., Zanna, M. P., \& Esses, V. M. (1993). Assessing the structure of prejudicial attitudes: The case of attitudes toward homosexuals. Journal of Personality and Social Psychology, 65, 1105-1118.

Haney, J. L. (2016). Predictors of homonegativity in the United States and the Netherlands using the fifth wave of the World Values Survey. Journal of Homosexuality, 63, 1355-1377.

Heck, N. C., Fientje, A., \& Cochran, B. N. (2011). Offsetting risks: High School gay-straight alliances and lesbian, gay, bisexual, and transgender (LGBT) youth. School Psychology Quarterly, 26, $161-174$.

Hegarty, P. (2010). A stone in the soup? Changes in sexual prejudice and essentialist beliefs among British students in a class on LGBT psychology. Psychology and Sexuality, 1, 3-20.

Herek, G. M. (1997). The HIV epidemic and public attitudes toward lesbians and gay men. In M. P. Levine, P. Nardi, \& J. Gagnon (Eds.), In changing times: Gay men and lesbians encounter HIV/AIDS (pp. 191-218). Chicago: University of Chicago Press.

Herek, G. M. (1988). Heterosexuals' attitudes toward lesbians and gay men: Correlates and gender differences. The Journal of Sex Research, 25, 451-477.

Herek, G. M. (2000). The psychology of sexual prejudice. Current Directions in Psychological Science, 9, 19-22.

Herek, G. M. (2007). Confronting sexual stigma and prejudice: Theory and practice. Journal of Social Issues, 63, 905-925.

Herek, G. M., \& McLemore, K. A. (2013). Sexual prejudice. Annual Review of Psychology, 64, 309-333.

Hillman, J., \& Martin, R. A. (2002). Lessons about gay and lesbian lives: A spaceship exercise. Teaching of Psychology, 29(4), 308-311.

Hill, D. B., \& Willoughby, B. L. B. (2005). The development and validation of the genderism and transphobia scale. Sex Roles, 53, 531-544.

Hodson, G., Choma, B. L., \& Costello, K. (2013). Experiencing alien-nation: Effects of a simulation intervention on attitudes toward homosexuals. Journal of Experimental Social Psychology, 45, 974-978.

Hoffarth, M. R., \& Hodson, G. (2014). Is subjective ambivalence toward gays a modern form of bias? Personality and Individual Differences, 69, 75-80.

Hoffarth, M. R., \& Hodson, G. (2016). Who needs imagined contact? Replication attempts examining previous contact as a potential moderator. Social Psychology, 47, 118-124.

Hong, S. J., Espelage, D. L., \& Kral, M. J. (2011). Understanding suicide among sexual minority youth in America: An ecological systems analysis. Journal of Adolescence, 34, 885-894.

Hubbard, R. R., Snipes, D. J., Perrin, P. B., Morgan, M. R., DeJesus, A., \& Bhattacharyya, S. (2013). Themes in hetersexuals responses when challenging LGBT prejudice. Sexuality Research and Social Policy, 10(4), 269-278. https://doi.org/10.1007/s13178-013-0127-4

Hudepohl, A. D., Parrot, D. J., \& Zeichner, A. (2010). Heterosexual men's anger in response to male homosexuality: Effects of erotic and non-erotic depictions of male-male intimacy and sexual prejudice. Journal of Homosexuality, 57, 1022-1038. https://doi.org/10.1080/ 00918369.2010 .503511

Inbar, Y., Pizarro, D. A., Knobe, J., \& Bloom, P. (2009). Disgust sensitivity predicts intuitive disapproval of gays. Emotion, 9, 435-439. 
Jäckle, S., \& Wenzelburger, G. (2015). Religion, religiosity, and the attitudes toward homosexuality-a multilevel analysis of 79 countries. Journal of Homosexuality, 62, 207-241.

Jones, D. (2010). A WEIRD view of human nature skews psychologists' studies. Science, 328, 1627.

Kerr, P. S., \& Holden, R. R. (1996). Development of the gender role beliefs scale (GRBS). Journal of Social Behavior and Personality, 11, 3-15.

Krolikowski, A. M., Rinella, M., \& Radcliff, J. J. (2016). The influence of the expression of subtle and blatant sexual prejudice on personal prejudice and identification with the expresser. Journal of Homosexuality, 63, 228-249.

Kuyper, L. (2015). Wel trouwen, niet zoenen: De houding van de Nederlandse bevolking tegenover lesbische, homoseksuele, biseksuele en transgender personen 2015 (SCP-publication 2015-12). The Netherlands Institute for Social Research [SCP]. Retrieved from the Netherlands Institute for Social Research website.

Lannutti, P. J., \& Lachlan, K. A. (2007). Assessing attitude toward same-sex marriage: Scale development and validation. Journal of Homosexuality, 53, 113-133.

Lee, W., \& Cunningham, G. B. (2016). Gender, sexism, sexual prejudice, and identification with U.S. football and men's figure skating. Sex Roles, 74, 1-8.

Legault, L., \& Gutsell, J. N., \& Inzlicht, M. (2011). Ironic effects of anti-prejudice messages: How motivational intervention reduces (but also increases) prejudice. Psychological Science, 22, $1472-1477$.

Lick, D. J., \& Johnson, K. L. (2014). Perceptual underpinnings of antigay prejudice: negative evaluations of sexual minority women arise on the basis of gendered facial features. Personality and Social Psychology Bulletin, 40, 1178-1192.

Loehr, A., Doan, L., \& Miller, L. R. (2015). The role of selection effects in the contact hypothesis: Results from a U.S. national survey on sexual prejudice. Archives of Sexual Behavior, 44, 2111-2123.

Major, B., Kaiser, C., \& McCoy, S. K. (2003). It's not my fault: When and why attributions to prejudice protect self-esteem. Personality and Social Psychology Bulletin, 29, 772-781.

Marshal, M. P., Dietz, L. J., Friedman, M. S., Stall, R., Smith, H. A., McGinley, J., Thoma, B. C., Murray, P. J., Anthony, M. H. P., D’Augelli, R., \& Brent, D. A. (2011). Suicidality and depression disparities between sexual minority and heterosexual youth: A meta-analytic review. Journal of Adolescent Health, 49, 115-123. https://doi.org/10.1016/j.jadohealth.2011.02.005

McConahay, J. B. (1986). Modern racism: Ambivalence and modern racism Scale. In J. F. Dovidio and S. L. Gaertner (Eds.), Prejudice, discrimination and racism (pp. 91-125). San Diego: Academia Press.

Miles, E., \& Crisp, R. J. (2014). A meta-analytic test of the imagined contact hypothesis. Group Processes and Intergroup Relations, 17, 3-26.

Monto, M. A., \& Supinski, J. (2014). Discomfort with homosexuality: A new measure captures differences in attitudes toward gay men and lesbians. Journal of Homosexuality, 61, 899-916.

Morrison, M. A, \& Morrison, T. G. (2003). Development and validation of a scale measuring modern prejudice toward gay men and lesbian women. Journal of Homosexuality, 43, 15-37.

Morrison, M. A., Morrison, T. G., \& Franklin, R. (2009). Modern and old-fashioned homonegativity among samples of Canadian and American university students. Journal of Cross-Cultural Psychology, 40, 523-542.

Morrison, M. A., \& Morrison, T. G. (2011). Sexual orientation bias toward gay men and lesbian women: Modern homonegative attitudes and their association with discriminatory behavioral intentions. Journal of Applied Social Psychology, 41 (11), 2573-2599.

Moss-Racusin, C. A., Van der Toorn, J., Dovidio, J. F., Brescoll, V. F., Graham, M. J., \& Handelsman, J. (2014). Scientific diversity interventions. Science, 343, 615-616.

Oransky, M., \& Fisher, C. B. (2009). The development and validation of the meanings of adolescent masculinity scale. Psychology of Men \& Masculinity, 10, 57-72.

Orosz, G., Banki, E., Bothel, B., Toth-Kiraly, I., \& Tropp, L. R. (2016). Don’t judge a living book by its cover: Effectiveness of the living library intervention in reducing prejudice toward Roma and LGBT people. Journal of Applied Social Psychology, 46, 510-517.

Page-Gould, E., Mendoza-Denton, R., \& Tropp, L. R. (2008). With a little help from my crossgroup friend: Reducing anxiety in intergroup contexts through cross-group friendship. 
Journal of Personality and Social Psychology, 95(5), 1080-1094. https://doi.org/10.1037/00223514.95.5.1080

Parrott, D. J. (2009). Aggression toward gay men as gender role enforcement: Effects of male role norms, sexual prejudice, and masculine gender role stress. Journal of Personality, 77, $1137-$ 1166.

Parrott, D. J., \& Gallagher, K. E. (2008). What accounts for heterosexual women's negative emotional responses to lesbians?: Examination of traditional gender role beliefs and sexual prejudice. Sex Roles, 59, 229-239.

Parrot, D. J., \& Lisco, C. G. (2015). Effects of alcohol and sexual prejudice on aggression toward sexual minorities. Psychology of Violence, 5, 256-265.

Pearl, M. L., \& Galupo, M. P. (2007). Development and validation of the attitudes toward same-sex marriage scale. Journal of Homosexuality, 53, 117-134.

Pettigrew, T. F., \& Tropp, L. R. (2006). A meta-analytic test of intergroup contact theory. Journal of Personality and Social Psychology, 90, 751-783.

Pokorny, J., Jason, L., Schoeny, M., Townsend, S., \& Curie, C. (2001). Do participation rates change when active consent procedures replace passive consent? Evaluation Review, 25(5), 567580 .

Poteat, V. P. (2015). Individual psychological factors and complex interpersonal conditions that predict LGBT-affirming behavior. Journal of Youth and Adolescence, 44, 1494-1507.

Poteat, V. P., \& Vecho, O. (2016). Who intervenes against homophobic behavior? Attributes that distinguish active bystanders. Journal of School Psychology, 54, 17-28.

Shelton, J. N., Richeson, J. A., \& Vorauer, J. D. (2006). Threatened identities and interethnic interactions, European Review of Social Psychology, 17, 321-358.

Roderick, T., McCammon, S. L., Long, T. E., \& Allred, L. J. (1998). Behavioral aspects of homonegativity. Journal of Homosexuality, 36, 79-88.

Romero, D. H., Morera, O. F., \& Wiebe, J. S. (2015). Assessing the gender invariance of the modern homonegativity scale. Journal of Homosexuality, 62, 1539-1559.

Rostosky, S. S., Black, W. W., Riggle, E. D. B., \& Rosenkrantz, D. (2015). Positive aspects of being a heterosexual ally to lesbian, gay, bisexual and transgender (LGBT) people. American Journal of Orthopsychiatry, 85, 331-338.

Shutts, K., Kenward, B., Falk, H., Ivegran, A., \& Fawcett, C. (2017). Early preschool environments and gender: Effects of gender pedagogy in Sweden. Journal of Experimental Child Psychology, 162,1-17. https://doi.org/10.1016/j.jecp.2017.04.014

Smith, S. J., Axelton, A. M., \& Saucier, D. A. (2009). The effects of contact on sexual prejudice: A meta-analysis. Sex Roles, 61, 178-191. https://doi.org/10.1007/s11199-009-9627-3

Spence, J. T., \& Hahn, E. D. (1997). The attitudes toward women scale and attitude change in college students. Psychology of Women Quarterly, 21, 17-34.

Stotzer, R. L., \& Shih, M. (2012). The relationship between masculinity and sexual prejudice in factors associated with violence against gay men. Psychology of Men \& Masculinity, 13, 136142.

Thompson, E. H., Jr., \& Pleck, J. H. (1986). The structure of male norms. American Behavioral Scientist, 29, 531-543.

Tompkins, T. L., Livesay, K., Shields, C. N., Talbot, C. C., \& Hillman, K. M. (2014, June). Reducing stigma toward the transgender community: An evaluation and perspective-taking intervention [Poster presentation]. Retrieved from http://digitalcommons.linfield.edu/psycfac_pres/1

Toomey, R. B., McGuire, J. K., \& Russell, S. T. (2012). Heteronormativity, school climates, and perceived safety for gender nonconforming peers. Journal of Adolescence, 35, 187-196.

Turner, R. N., Crisp, R. J., \& Lambert, E. (2007). Imagining intergroup contact can improve intergroup attitudes. Group Processes \& Intergroup Relations, 10, 427-441.

Van der Toorn, J., Jost, J. T., Packer, D., Noorbaloochi, S., \& Van Bavel, J. J. (2017). In defense of tradition: Religiosity, conservatism, and opposition to same-sex marriage in North America. Personality and Social Psychology Bulletin, 43(10), 1455-1468. https://doi.org/ $10.1177 / 0146167217718523$ 
Vang, M. H., \& Fox, J. (2014). Race in virtual environments: Competitive versus cooperative games with black or white avatars. Cyberpsychology, Behavior, and Social Networking, 17(4), 235240. https://doi.org/10.1089/cyber.2013.0289

Vanwesenbeeck, I., Westeneng, J., De Boer, T., Reinders, J., \& Van Zorge, R. (2015). Lessons learned from a decade implementing comprehensive sexuality education in resource poor settings: The world starts with me. Sex Education, 16(5), 471-486. https://doi.org/ 10.1080/14681811.2015.1111203

Velez, J. A., Mahood, C., Ewoldsen, D. R., \& Moyer-Gusé, E. (2014). Ingroup versus outgroup conflict in the context of violent video game play: The effect of cooperation on increased helping and decreased aggression. Communication Research, 41(5), 607-626. https://doi.org/ $10.1177 / 0093650212456202$

Vincent, W., Parrott, D. J., \& Peterson, J. L. (2011). Combined effects of masculine gender-role stress and sexual prejudice on anger and aggression toward gay men. Journal of Applied Social Psychology, 41, 1237-1257.

Walch, S. E., Sinkkanen, K. A., Swain, E. M., Fransisco, J., Breaux, C. A., \& Sjoberg, M. D. (2012). Using intergroup contact theory to reduce stigma against transgender individuals: Impact of a transgender speaker panel presentation. Journal of Applied Social Psychology, 42, 25832605.

Walker, B. H., Sinclair, H. C., \& MacArthur, J. (2015). Social norms versus social motives: The effects of social influence and motivation to control prejudiced reactions on the expression of prejudice. Social Influence, 10, 55-67.

Walls, N. E., Kane, S. B., \& Wisneski, H. (2010). Gay-straight alliances and school experiences of sexual minority youth. Youth \& Society, 41, 307-332.

Walters, A. S., \& Rehma, K. (2013). Avenue T: Using film as entrée in teaching about transgender. Sex Education, 13(3), 336-348.

Woodford, M. R., Chonody, J. M., LCSW, Kulick, A., Brennan, D. J., \& Renn, K. (2015). The LGBQ microaggressions on campus scale: A scale development and validation study. Journal of Homosexuality, 62, 1660-1687.

Wright, L. W. Jr., Adams, H. E., \& Bernat, J. (1999). Development and validation of the homophobia scale. Journal of Psychopathology and Behavioral Assessment, 21, 337-347.

Yee, N., \& Bailenson, J. N. (2006). Walk a mile in digital shoes: The impact of embodied perspectivetaking on the reduction of negative stereotyping in immersive virtual environments. Proceedings of PRESENCE 2006: The 9th Annual International Workshop on Presence. August 24-26, Cleveland, Ohio, USA.

FLORIEN CRAMWINCKEL (PhD, 2016, Utrecht University) is assistant professor of interdisciplinary social sciences at Utrecht University, the Netherlands. She has a background in social psychology. In her current position as an assistant professor, she focuses on the reduction of prejudice against sexual minorities. She studies measures to assess sexual orientation- and gender identity prejudice and investigates the effectiveness of existing interventions to reduce prejudice. This also fits with her volunteer work for COC Midden-Nederland-an organization that strives for equal rights and emancipation of LGBTQ's. In her PhD research, she focused on social psychological insights into moral reactions. She investigated questions such as: how do people respond to others who take a moral stance; why is this response (often) so negative; how to reduce these negative consequences? She focused on several different areas, such as homosexuality, discrimination, and vegetarianism. 
DAAN SCHEEPERS (PhD, 2002, University of Amsterdam) is associate professor of social and organizational psychology at Leiden University, the Netherlands. His research centers on group processes, intergroup relations (the psychology of "us and them") and social identity. More specifically, in his research Daan addresses a range of topics including the effects of status and power differences within and between groups, social identity threat, stereotyping, prejudice, and intergroup dynamics. In several lines of research Daan applies psychophysiological methods, for example on the basis of the biopsychosocial model (Blascovich, 2008). This methodology makes it possible to measure cardiovascular response profiles that are indicative of "challenge" and "threat" motivational states.

JOJANNEKE VAN DER TOORN (PhD, 2010, New York University) is professor of lesbian, gay, bisexual and transgender workplace inclusion at Leiden University, and associate professor of social and organizational psychology at Utrecht University. She studies diversity and inequality in society and organizations with a focus on the social psychological mechanisms involved in how, why, and when people resist, provide support for, or directly engage in social change. In her work, Jojanneke strives for a combination of scientific quality and societal impact. Through active engagement with industry, government, and civil society she bridges science and society with the ultimate aim of contributing to evidence-based diversity policy. Jojanneke initiated the Political Psychology Meetings in the Netherlands, served on the Governing Council of the International Society of Political Psychology, and is Associate Editor for the Journal of Social and Political Psychology. In recognition of her academic work, she received the Gratama Science Prize for excellent young researchers. 